\title{
Competência ortográfica e metafonológica: influências e correlações na leitura e escrita de escolares da $4^{\text {a }}$ série
}

\author{
Orthographic and metaphonological competences: influences and \\ correlations with reading and writing abilities of $4^{\text {th }}$ grade students
}

\author{
Juliana Faleiros Paolucci' ${ }^{1}$, Clara Regina Brandão de Ávila²
}

\begin{abstract}
RESUMO
Objetivo: Estudar o desempenho de escolares da $4^{a}$ série em tarefas de leitura e escrita e de consciência fonológica. Métodos: Trinta e dois escolares de $4^{\mathrm{a}}$ série (50,0\% meninas), entre nove e 11 anos, foram avaliados segundo os procedimentos: anamnese, avaliação da leitura, escrita (54 itens linguísticos) e consciência fonológica. Foram divididos em: GPI: escreveram e, após, leram em voz alta; GPII: leram em voz alta e, após, escreveram; GCI: apenas escreveram; GCII: apenas leram. Resultados: Na escrita, GPII apresentou as maiores médias de acerto, sendo que GPI, GPII e GCI apresentaram melhor desempenho para as palavras frequentes, seguido das pseudopalavras e das de baixa frequência. Na leitura, os desempenhos dos GPI, GPII e GCII foram semelhantes, sendo que GPI e GPII apresentaram mais acertos para as pseudopalavras, seguido das de alta frequência. A correlação entre consciência fonológica e escrita mostrou-se moderada e entre consciência fonológica e leitura e entre escrita e leitura foi bem fraca. Conclusões: A consciência fonológica mostrou moderada correlação com a escrita e baixa com a leitura; a característica psicolinguística baixa familiaridade determinou as maiores médias de erro, tanto na leitura quanto na escrita.
\end{abstract}

Descritores: Leitura; Escrita manual; Avaliação

\section{INTRODUÇÃO}

Os mecanismos do aprendizado da leitura e da escrita contêm elementos comuns, embora a literatura não seja unânime ao tentar descrever como as duas formas se articulam. Durante muito tempo pensou-se que escrita e leitura nada mais eram que fenômenos inversos de codificação e decodificação e que quem aprendesse a ler também aprenderia a escrever. $\mathrm{O}$ início do aprendizado do sistema alfabético, para a leitura ou a escrita, demonstra ter uma base comum. Este requer que a criança desenvolva competências metalinguísticas que lhe permitam direcionar sua atenção para os diferentes segmentos das palavras e associando cada som identificado com uma letra específica, co-articulá-lo, compondo oralmente a palavra lida, ou identificando a letra correspondente, escrever a palavra pretendida. Quanto melhor a capacidade metalinguística de consciência fonológica, maior será o sucesso no aprendizado inicial da leitura e escrita ${ }^{(1-7)}$.

Trabalho realizado no Departamento de Fonoaudiologia da Universidade Federal de São Paulo - UNIFESP - São Paulo (SP), Brasil.

(1) Pós-graduanda em Distúrbios da Comunicação Humana pela Universidade Federal de São Paulo - UNIFESP - São Paulo (SP), Brasil.

(2) Doutora, Professora Associada do Departamento de Fonoaudiologia da Universidade Federal de São Paulo - UNIFESP - São Paulo (SP), Brasil.

Endereço para correspondência: Juliana Faleiros Paolucci. R. Santa Cruz, 805/102, Vila Mariana, São Paulo - SP, CEP 04121-000.

E-mail: jfpaolucci@bol.com.br

Recebido em: 24/10/2007; Aceito em: 28/10/2008
Fatores como os processamentos da informação fonológica seriam, portanto, considerados fundamentais nos momentos iniciais do aprendizado. A maioria das pesquisas em leitura e escrita tem focalizado essa relação. Porém, o progresso na aprendizagem da leitura e da escrita sofre, também, a influência de diferentes fatores que promovem o aprendizado de padrões ortográficos, associados com a pronúncia baseada nos padrões fonológicos. Assim, com o aprendizado contínuo e progressivo o estudante alcança a etapa ortográfica durante a qual o reconhecimento e leitura das palavras ocorrem por via direta de acesso lexical e semântico a partir de certas características gráficas da palavra, armazenadas ortograficamente ${ }^{(8-9)}$. Para a escrita, o mesmo banco de memória ortográfica é ativado no sentido da obtenção da produção correta.

Evidentemente, o aprendizado ortográfico requer, dentre outras capacidades o correto processamento das informações fonológicas e do desenvolvimento metalinguístico relacionado a funções de conhecimento gramatical e à exposição contínua e formal ao material escrito ${ }^{(10)}$. Essa exposição é caracterizada por diferenças de frequência de aparecimento da palavra no idioma falado e escrito, e impõe influências no processo do aprendizado ortográfico ${ }^{(11)}$.

Nesse contexto, não se pode deixar de considerar ou dar importância à possibilidade da familiaridade da palavra influenciar o aprendizado da leitura e/ou da escrita bem como a avaliação de ambas. Muitos autores têm descrito o efeito 
lexical como a possibilidade da criança, após ter lido um item linguístico, associá-lo com alguma palavra já conhecida, promovendo o aprendizado e facilitando a sua escrita ${ }^{(12-14)}$.

Além da frequência de ocorrência de uma palavra, outro fator que exerce influência no desempenho é a sua ortografia. As palavras de escrita irregular podem produzir mais erros que aquelas de escrita regular e entre estas, melhores desempenhos podem ser observados com palavras de transparência ortográfica do que com as de opacidade. Entretanto, o efeito de regularidade pode ser observado de formas diferentes para a leitura e para a escrita de palavras e pseudopalavras. Ou seja, a avaliação desse efeito é dependente da tarefa realizada, se leitura ou escrita ${ }^{(15)}$.

A familiaridade com a palavra está relacionada à frequência de seu aparecimento na língua. As representações ortográficas são construídas a partir de metanálises realizadas pela criança e das repetidas exposições às palavras escritas. A palavra cuja escrita já se tornou familiar pode ser lida pela rota lexical. Por outro lado, palavras com baixa frequência de aparecimento podem não possuir representações ortográficas no léxico mental e, portanto, serem lidas pela rota fonológica ${ }^{(16)}$. Indivíduos sem dificuldades podem usar de maneira equilibrada dos processos lexicais e fonológicos durante a leitura ${ }^{(12-14,17)}$.

As palavras de alta frequência tendem a ser lidas e/ou escritas mais rapidamente e/ou corretamente do que aquelas com baixa ocorrência. No entanto, diferenças individuais no nível dos mecanismos viso-ortográficos podem modificar esse fato, sendo possível observar diferentes desempenhos. $\mathrm{Ou}$ seja, algumas crianças lêem e/ou escrevem melhor, mesmo as palavras irregulares, do que pseudopalavras, enquanto outras fazem o inverso ${ }^{(18)}$.

O uso de pseudopalavras, principalmente em materiais de avaliações clínicas da leitura e da escrita, é imprescindível, na medida em que fornece informações sobre as capacidades fonológicas de codificação e decodificação do indivíduo que está sendo avaliado. Estas serão lidas ou escritas, sempre pela rota fonológica.

É extremamente relevante a escolha do material para a avaliação do desempenho de escolares em tarefas de leitura e escrita. O balanceamento de variáveis psicolinguísticas (frequência, regularidade, extensão e lexicalidade) desse material pode determinar a prevalência de erros nas provas de investigação.

Entende-se que os processos relacionados à escrita de palavras são mais complexos do que os da leitura, mas que ambos os desempenhos são influenciados pelas características dos estímulos ${ }^{(19-20)}$.

O quanto a familiaridade com o item escrito depende de conhecimento prévio e quão longevo ou arraigado deve ser esse conhecimento para influenciar o desempenho tanto na leitura como na escrita, ainda não se sabe. Como também não há consenso sobre os mecanismos (ou mesmo de suas existências) de influência da escrita sobre a leitura ou da leitura sobre a escrita. Ou ainda sobre a existência da influência da consciência fonológica sobre a leitura e a escrita mais ou menos ortográfica de escolares que já cursam a $4^{\mathrm{a}}$ série do Ensino Fundamental e que, portanto, já deveriam dominar a maioria das regras ortográficas do Português Brasileiro para ler e escrever.
A maioria das pesquisas relacionadas ao estudo do domínio e competência ortográfica focaliza ou a escrita ou a leitura e, mais frequentemente, a primeira. A maioria também investiga o processo de aprendizado nas séries iniciais. No Brasil predominam os estudos que buscam a compreensão entre possíveis relações entre a aprendizagem da leitura e da escrita e capacidades metalinguísticas e destes, a maioria está voltada para a investigação da consciência fonológica ${ }^{(21)}$.

Diferentemente dos escolares das séries iniciais, estudantes da $4^{\mathrm{a}}$ série do Ensino Fundamental já aprenderam ou desenvolveram outras capacidades que lhe permitem reconhecer rapidamente e escrever palavras tanto mais corretamente quanto mais familiares forem. Sabe-se, entretanto, que ainda apresentam algumas inabilidades do uso de regras ortográficas tanto na escrita quanto na leitura.

Compreender como lêem e escrevem alunos de $4^{a}$ série é de importância basilar, uma vez que no ano seguinte devem apresentar outras competências sociais e comunicativas para enfrentarem novo modo de organização que encontrarão no segundo ciclo do Ensino Fundamental.

Por isso, esta pesquisa ateve-se em estudar o desempenho de escolares da $4^{a}$ série em tarefas de leitura e escrita e de consciência fonológica.

Levantamos como hipóteses que os estudantes de $4^{\mathrm{a}}$ série leriam e escreveriam mais corretamente palavras de alta frequência, seguidas das de baixa frequência e por último das pseudopalavras, evidenciando o efeito de familiaridade sobre o aprendizado e que a exposição quase imediata aos itens linguísticos não influenciariam esses desempenhos; que a exposição imediatamente anterior ao material escrito deveria influenciar igualmente a leitura e a escrita; que não haveria correlação entre o desempenho em consciência fonológica e as tarefas de leitura ou escrita nesses desempenhos de alunos da $4^{a}$ série, para os quais, a via direta, lexical e ortográfica da leitura já estaria desenvolvida.

\section{MÉTODOS}

Este trabalho foi aprovado pelo Comitê de Ética (0859/04) da Universidade Federal de São Paulo. A pesquisa foi iniciada após assinatura dos termos de esclarecimento pela diretoria da escola onde a coleta de dados foi realizada e pelos pais ou responsáveis pelos escolares.

Para cumprir os objetivos deste trabalho foram avaliadas 35 crianças do sexo feminino e masculino, com idades entre nove e 11 anos, alunos da $4^{\mathrm{a}}$ série do ensino fundamental de uma escola da rede particular de ensino do Município de São Paulo - SP.

Após entrevista com os pais e educadores, foram selecionadas para a pesquisa as crianças que se enquadraram nos seguintes critérios de inclusão pré-estabelecidos: ausência de relato de retenção em alguma série ou de dificuldades escolares; ausência de queixa auditiva; ausência de queixas relacionadas a alterações de capacidades motoras ou psicomotoras; residência em um lar de pessoas falantes do Português Brasileiro; inexistência de queixas relacionadas a problemas neurológicos e/ou psicológicos; referência de adequação das capacidades intelectuais para o aprendizado 
da linguagem escrita, de compreensão da linguagem falada, de linguagem expressiva, de rendimento de leitura e escrita (correspondente ao esperado para a idade cronológica, inteligência e escolaridade), aprovação nas triagens de linguagem oral compreensiva e expressiva, de leitura e de escrita e do processamento auditivo.

Após a indicação dos professores, foram chamados um menino e uma menina, de forma consecutiva e progressiva, até que se completassem 32 escolares (50\% meninas) que tivessem passado na triagem. Esta foi realizada individualmente, por meio da execução de tarefas de linguagem expressiva (a partir de conversa espontânea dirigida), de linguagem compreensiva (reconto de texto contado oralmente), de leitura (leitura de texto adequado à escolaridade) e escrita (ditado de palavras) (22-23). Também foram submetidos à avaliação simplificada do Processamento Auditivo ${ }^{(24)}$, como parte componente da triagem.

Foram excluídas da amostra três crianças que apresentaram resultados aquém do esperado para a idade e escolaridade nas tarefas propostas para a triagem. Seus pais e professores foram devidamente orientados quanto à importância da realização de avaliação fonoaudiológica completa e receberam indicações ou encaminhamentos para serviços especializados.

Ao final, foram selecionados 32 escolares, agrupados aleatoriamente da seguinte forma: dois Grupos Pesquisa - GP I: oito escolares (quatro meninas) que escreveram, sob ditado, a lista de palavras e pseudopalavras e, em seguida, leram em voz alta os mesmos itens linguísticos que haviam escrito; - GP II: oito escolares (quatro meninas) que leram em voz alta a lista de palavras e pseudopalavras e em seguida escreveram, sob ditado, os mesmos itens linguísticos que foram lidos. Foram estabelecidos dois Grupos para Comparação - GC I: oito escolares (quatro meninas) que realizaram apenas a tarefa de escrita sob ditado da lista de palavras e pseudopalavras; - GC II: oito escolares (quatro meninas) que realizaram apenas a leitura da lista de palavras e pseudopalavras.

O material linguístico foi constituído de palavras de diferentes frequências de aparecimento e diferentes extensões (escolhidas e categorizadas junto às professoras das classes frequentadas pelos alunos, a partir de análise do material escolar) e pseudopalavras ${ }^{(25)}$.

A lista de palavras selecionadas constou de:

20 palavras de alta frequência:

- dissilábicas: de transparência ortográfica (3): pato, fada, boné; de opacidade ortográfica (5): mesa, carro, fingir, atrás, anzol;

- trissilábicas: de transparência ortográfica (3): jogador, campeão, árvore; de opacidade ortográfica (9): torneira, guerrilha, chuteira, vassoura, peixinho, assistir, altura, próximo, horário;

15 palavras de baixa frequência:

- dissilábicas (4): de transparência ortográfica: diva, feno, pito; e de opacidade ortográfica: sebo;

- trissilábicas (15): de opacidade ortográfica: gravidez, cresceram, excedeu, flexível, detectar, sentença, letreiro, frequente, negócio;

- polissilábicas (2): de opacidade ortográfica: exagerou, magnífico.

\section{4 pseudopalavras:}

- dissilábicas (12): tupa, dofé, bunfe, tavor, melha, nusa, virru, morja, dumaz, queuci, gliro, praixo;

- trissilábicas (11): flômina, balsomão, cinhela, daguite, jiborá, brossudam, chediza, umpegol, oxínio, andaço, zosvibe;

- polissilábica (1) exobradou (pronunciada como ezobradou).

Todos os escolares foram submetidos aos seguintes procedimentos:

1. Anamnese: com a finalidade de obter informações sobre nome, idade e escolaridade.

2. Avaliação da escrita: foi realizado o ditado de palavras e pseudopalavras, na mesma ordem, para todas as crianças, estas foram escritas a lápis em folha de papel sulfite. Não foi medido o tempo utilizado para escrevê-las e foi oferecida a possibilidade de corrigi-las caso necessário. Posteriormente, foram identificados e assinalados os erros ortográficos de cada criança, estes não foram analisados quanto ao tipo. Foi considerado acerto quando o registro da palavra correspondia à grafia adotada pelas normas e regras da língua portuguesa. Nas pseudopalavras, a escrita foi considerada correta quando esta correspondia corretamente os fonemas aos grafemas. A escrita deveria corresponder à pronúncia correta da palavra, respeitando também as regras da língua aplicadas às palavras. No caso dos fonemas com múltiplas representações, foi considerado acerto quando este era reproduzido por um dos grafemas aceitos em cada contexto.

3. Avaliação da leitura: foi oferecida uma folha de papel sulfite na qual estava escrita em letra imprensa (Arial 12) a lista de palavras e pseudopalavras, na mesma ordem para todas as crianças, para serem lidas em voz alta. Não foi considerado o tempo necessário para a realização da tarefa. A leitura foi gravada em fita cassete com a utilização de um gravador Mini Cassette Recorder Panasonic - RQL11. Posteriormente, foram identificados e assinalados os erros de cada criança (estes não foram analisados quanto ao tipo). A pronúncia das palavras foi considerada correta quando se respeitou: a correspondência grafema-fonema adequada ao contexto; padrão correto de tonicidade da língua; pronúncia da vogal como indicada pelo acento.

4. Avaliação da Consciência Fonológica: foi aplicado o Teste de Consciência Fonológica ${ }^{(24)}$. Este teste consiste de seis tarefas fonológicas: síntese fonêmica, identificação de rimas, segmentação, exclusão e transposição fonêmica. As tarefas foram realizadas nesta mesma ordem, após instrução e pelo menos um exemplo, as respostas foram todas registradas. Foi considerado adequado o teste quando, do total de 30 itens, a criança acertou 29 ou os 30 destes.

A avaliação foi realizada individualmente em uma sala silenciosa, na própria escola. Os quatro grupos foram submetidos, sequencialmente, à tarefa de leitura e/ou de escrita e ao teste de consciência fonológica ${ }^{(24)}$. Os grupos diferiram pela ordem de execução das tarefas de leitura e escrita.

Compararam-se os desempenhos na escrita do GPI, GPII com GCI e o desempenho na leitura do GPI, GPII com GCII, segundo a variável psicolinguística frequência do item lin- 
Tabela 1. Número médio de acertos, para a tarefa de ditado, segundo os grupos e as características psicolinguísticas das palavras

\begin{tabular}{llccccc}
\hline Grupo & $\begin{array}{l}\text { Característica } \\
\text { psicolinguística }\end{array}$ & Média & Mediana & Desvio-padrão & Mínimo & Máximo \\
\hline \multirow{3}{*}{ GP I } & Alta frequência & 17,00 & 17,00 & 2,14 & 13,00 & 20,00 \\
& Baixa frequência & 9,00 & 9,00 & 2,39 & 5,00 & 12,00 \\
\hline \multirow{2}{*}{ GP II } & Pseudopalavra & 16,13 & 15,50 & 2,95 & 13,00 & 21,00 \\
& Alta frequência & 19,38 & 19,50 & 0,74 & 18,00 & 20,00 \\
& Baixa frequência & 10,50 & 10,00 & 2,27 & 8,00 & 14,00 \\
\multirow{2}{*}{ GC I } & Pseudopalavra & 17,88 & 20,00 & 3,52 & 12,00 & 21,00 \\
& Alta frequência & 18,38 & 19,00 & 1,69 & 15,00 & 20,00 \\
& Baixa frequência & 8,63 & 8,50 & 2,07 & 6,00 & 1311 \\
\end{tabular}

Legenda: GP = Grupo de Pesquisa; GC = Grupo para Comparação

guístico. Após, compararam-se o desempenho nas tarefas de leitura e escrita com o de consciência fonológica.

\section{Método estatístico}

Para as comparações dos desempenhos, calculados pelo número de acertos nas diferentes tarefas, utilizaram-se o coeficiente de correlação de Pearson e Modelos de regressão (Poisson e Beta), os quais descrevem relações lineares. Modelos de regressão empregam princípios para estudar as relações entre variáveis dentro de um sistema incerto. Para tal, são empregados diferentes processos cujo principal objetivo é prever o valor de uma característica a partir do conhecimento de outra variável. O nível de significância para os testes foi sempre o valor $\mathrm{p}<0,0001$, assinalado com um asterisco os valores significantes.

O coeficiente de correlação de Pearson é uma medida do grau de relação linear entre duas variáveis quantitativas. Este coeficiente varia entre os valores -1 e 1 . $O$ valor 0 (zero) significa que não há relação linear, o valor 1 indica uma relação linear perfeita e o valor -1 também indica uma relação linear perfeita mas inversa, ou seja quando uma das variáveis aumenta a outra diminui. Quanto mais próximo estiver de 1 ou -1, mais forte é a associação linear entre as duas variáveis, o tamanho da variavel indica a força da correlação $(0,70$ para mais ou para menos indica uma forte correlação; 0,30 a 0,7 positivo ou negativo indica correlação moderada; 0 a 0,30 fraca correlação) ${ }^{(26)}$.

\section{RESULTADOS}

A Tabela 1 apresenta os desempenhos dos três grupos avaliados, na tarefa de ditado, segundo as características psicolinguísticas das palavras e mostra que o GP II, que leu as listas anteriormente à tarefa de escrita, apresentou as maiores médias de acerto tanto para palavras de alta frequência quanto para palavras de baixa frequência e pseudopalavras, apesar de não ter sido possível observar diferença estatisticamente significante entre o desempenho $(\mathrm{p}=0,1311)$ dos três grupos quando se comparou, separadamente, a escrita de palavras de alta frequência, de baixa frequência e das pseudopalavras.

Na Tabela 2 observa-se a comparação do número médio de acerto dos escolares do GPI, do GPII e do GCI na prova de ditado, analisada segundo as características psicolinguísticas das palavras. Foi possível observar diferença $(\mathrm{p}<0,0001)$ quando se comparou o número médio de acertos na escrita de palavras de baixa frequência tanto com o das palavras de alta frequência de ocorrência quanto com as médias de acerto nas pseudopalavras $(\mathrm{p}<0,0001)$. Ou seja, os escolares acertaram mais ao escrever palavras de alta frequência e pseudopalavras e erraram mais nas de baixa frequência. Não foi observada diferença estatisticamente significante entre os desempenhos com palavras de alta frequência e pseudopalavras $(\mathrm{p}=0,0955)$.

Tabela 2. Comparação das médias de escrita correta, na tarefa de ditado, segundo as características psicolinguísticas das palavras

\begin{tabular}{lcc}
\hline Variação & $\begin{array}{c}\text { Estimativa de } \\
\text { acerto }\end{array}$ & Valor de $\mathrm{p}$ \\
\hline Baixa frequência - alta frequência & $-5,2917$ & $<0001^{*}$ \\
Baixa frequência - pseudopalavras & $-5,5000$ & $<0001^{*}$ \\
Alta frequência - pseudopalavras & $-0,2083$ & 0,0955 \\
\hline
\end{tabular}

* Valores estatisticamente significantes

A Tabela 3 apresenta os desempenhos expressos em número médio de acertos dos três grupos avaliados na prova de leitura, distribuídos segundo as características psicolinguísticas dos itens escritos.

O GP I (que escreveu as palavras e pseudopalavras, antes de lê-las) e o GP II (não escreveram antes de ler) apresentaram a maior média de acertos na leitura de pseudopalavras. O GC II (mesma situação do GPII) apresentou a menor média de acertos na leitura de palavras de baixa frequência lidas corretamente. Entretanto, estatisticamente, essas diferenças não foram significantes: o desempenho dos três grupos foi semelhante quando se compararam as diferentes listas $(\mathrm{p}=0,6972)$.

Na Tabela 4 pode-se observar comparação do número médio de acerto dos escolares dos três grupos (GPI, GPII e GCII) na prova de leitura, analisada segundo as características psicolinguísticas das palavras.

Da mesma forma que na avaliação da escrita, a análise estatística mostrou diferença significante $(p<0,0001)$ quando se comparou o número médio de acertos na escrita de palavras de baixa frequência tanto com o das palavras de alta frequência de 
Tabela 3. Número médio de acertos, para a tarefa de leitura, segundo o grupo e características psicolinguísticas das palavras

\begin{tabular}{|c|c|c|c|c|c|c|c|}
\hline Grupos & $\begin{array}{l}\text { Característica } \\
\text { psicolinguística }\end{array}$ & Média & Mediana & Desvio-padrão & Mínimo & Máximo & Valor de $p$ \\
\hline & Alta frequência & 19,63 & 20,00 & 1,06 & 17,00 & 20,00 & \\
\hline \multirow[t]{3}{*}{ GP I } & Baixa frequência & 14,50 & 15,00 & 0,76 & 13,00 & 15,00 & \\
\hline & Pseudopalavras & 20,00 & 20,00 & 2,00 & 17,00 & 23,00 & \\
\hline & Alta frequência & 20,00 & 20,00 & 0,00 & 20,00 & 20,00 & \\
\hline \multirow[t]{3}{*}{ GP II } & Baixa frequência & 15,00 & 15,00 & 0,00 & 15,00 & 15,00 & 0,6972 \\
\hline & Pseudopalavras & 20,75 & 20,50 & 2,49 & 17,00 & 24,00 & \\
\hline & Alta frequência & 19,63 & 20,00 & 0,52 & 19,00 & 20,00 & \\
\hline \multirow[t]{2}{*}{ GC II } & Baixa frequência & 13,88 & 14,50 & 1,46 & 11,00 & 15,00 & \\
\hline & Pseudopalavras & 19,13 & 19,00 & 3,18 & 15,00 & 24,00 & \\
\hline
\end{tabular}

Legenda: GP = Grupo de Pesquisa; GC = Grupo para Comparação

ocorrência quanto com as médias de acerto nas pseudopalavras $(p<0,0001)$, sendo menor a quantidade de acertos para palavras de baixa frequência. Ou seja, os escolares acertaram mais ao ler palavras de alta frequência e pseudopalavras e erraram mais na leitura das de baixa frequência. Não foi observada diferença estatisticamente significante entre os desempenhos com palavras de alta frequência e pseudopalavras $(\mathrm{p}=0,0955)$.

Tabela 4. Comparação das médias de leitura correta, segundo as características psicolinguísticas das palavras

\begin{tabular}{lcc}
\hline Variação & $\begin{array}{c}\text { Estimativa de } \\
\text { acerto }\end{array}$ & Valor de $\mathrm{p}$ \\
\hline Baixa frequência - alta frequência & $-5,2917$ & $<0001^{*}$ \\
Baixa frequência - pseudopalavras & $-5,5000$ & $<0001^{*}$ \\
Alta frequência - pseudopalavras & $-0,2083$ & 0,8713 \\
\hline
\end{tabular}

* Valores estatisticamente significantes

Na Tabela 5 pode-se observar a correlação encontrada entre o desempenho dos escolares nas tarefas de escrita, leitura e consciência fonológica.

A análise mostra que a correlação encontrada entre consciência fonológica e escrita foi de 0,40 , ou seja, moderada e a correlação entre consciência fonológica e leitura foi bem fraca $(0,11)$. A correlação encontrada entre os desempenhos na escrita e na leitura foi bem fraca $(0,17)$.

Tabela 5. Correlação de entre os desempenhos nas tarefas de consciência fonológica, escrita e leitura

\begin{tabular}{lccc}
\hline & $\begin{array}{c}\text { Consciência } \\
\text { fonológica }\end{array}$ & Escrita & Leitura \\
\hline Consciência & 1,00 & 0,40 & 0,11 \\
fonológica & & $\mathrm{p}=0,0527$ & $\mathrm{p}=0,6258$ \\
Escrita & 1,00 & 0,17 \\
& & & $\mathrm{p}=0,5329$ \\
Leitura & & & 1,00 \\
\hline
\end{tabular}

\section{DISCUSSÃO}

Esta foi uma pesquisa realizada com 32 escolares (50,0\% meninas), estudantes da 4 a série do Ensino Fundamental, sem queixas ou indícios de alterações do aprendizado, regularmente matriculados em uma escola da rede particular, situada na zona Norte do município de São Paulo.

Este estudo foi realizado com o objetivo de analisar o desempenho de escolares da $4^{\text {a }}$ série em tarefas de leitura e escrita e de consciência fonológica e de buscar identificar possíveis correlações entre esses desempenhos, de acordo com a variável frequência de ocorrência das palavras, associados à familiaridade aos estímulos linguísticos. Investigou também se essa influência pôde ser determinada pela exposição aos itens escritos propiciada imediatamente antes à leitura e escrita dos mesmos.

Assim ao estudar o desempenho ortográfico na escrita dos escolares observou-se que, apesar de não haverem diferenças estatisticamente significantes entre os desempenhos dos grupos quando comparados à característica de frequência de aparecimento o GPII que, previamente ao ditado, havia lido os itens linguísticos, apresentou as maiores médias de acerto em relação aos demais grupos, tanto para palavras de alta frequência quanto para palavras de baixa frequência e pseudopalavras.

$\mathrm{Na}$ tarefa de leitura de itens isolados observou-se, novamente, que o GPII apresentou as médias mais altas de acerto. Entretanto, as diferenças em relação aos demais grupos foram menores do que as apresentadas na tarefa de escrita, o que tornou os desempenhos do GPI, GPII e GCII, mais semelhantes para cada tipo de frequência de aparecimento do item linguístico. Esses resultados sugerem que escrever a palavra antes não influenciou a leitura, uma vez que o GCII não leu nenhuma palavra, somente as escreveu.

Quando se observam conjuntamente os resultados da Tabela 1 e da Tabela 3 é possível perceber que a leitura mostrou mais acertos do que a escrita dos mesmos itens, independentemente do grupo estudado e da característica psicolinguística das palavras.

Relatos de alguns autores ${ }^{(19-20)}$ dão suporte aos encontrados neste trabalho, na medida em que descreveram os processos relacionados à escrita de palavras, mostrando-os mais complexos do que os da leitura.

Quando se analisou a influência da característica psicolinguística frequência de aparecimento, tanto na tarefa de escrita quanto na de leitura, observou-se que as palavras de baixa frequência determinaram a produção de mais erros do que as 
palavras familiares ou pseudopalavras, ou seja, a característica psicolinguística da palavra exerceu influência sobre a média de acerto, na leitura e escrita das mesmas $(\mathrm{p}<0,0001)$.

As palavras de baixa frequência selecionadas para compor a lista eram em maior número, tinham escrita irregular, e eram mais extensas; o que pode explicar o desempenho inferior dos alunos ao escreverem estas palavras. É preciso também lembrar que para a correção das palavras escritas na prova de ditado, foi considerado acerto quando o registro correspondia à grafia adotada pelas normas e regras da Língua Portuguesa, enquanto nas pseudopalavras foi considerada escrita correta quando esta correspondia corretamente os fonemas aos grafemas, admitindo-se todas as possibilidades de letras que escrevessem o item segundo a regra de dependência do contexto. Portanto, admitiram-se todas as possibilidades de competitividade de uso das letras, ou seja, a escrita deveria somente corresponder à pronúncia correta da palavra ditada. Este certamente contribuiu para aumentar o número de acertos da escrita dos escolares para as pseudopalavras.

Há pesquisa ${ }^{(3)}$ que dá suporte a este trabalho, na medida em que avaliando crianças com dificuldades também referiu números proporcionais de erros na escrita de palavras e de pseudopalavras.

Quanto aos desempenhos na prova de leitura dos três grupos avaliados (GPI, GPII, GCII), assim como na escrita (GPI, GPII, GCI), foi possível observar a presença de diferença estatisticamente significante $(\mathrm{p}<0001)$, com maior numero de erros ao ler e escrever palavras de baixa familiaridade.

A menor média de acertos para as palavras de baixa frequência pode ter sido obtida também ser devido à presença de mais palavras irregulares e mais extensas na lista.

Entretanto, é preciso considerar que para a realização da prova de leitura, o tempo de exposição à palavra a ser lida foi suficiente para que os escolares pudessem acessar inicialmente a rota fonológica alcançando após o acesso ao léxico e permitindo a auto-correção quando necessária, para que ocorresse a pronúncia da palavra ou pseudopalavra lida. Foi considerada correta, a pronúncia das palavras, quando se respeitou a correspondência grafema-fonema adequada ao contexto, condicionamento contextual, o padrão correto de tonicidade da língua e a pronúncia da vogal como indicada pelo acento ${ }^{(17)}$.

Os achados desta pesquisa encontram suporte em outros estudos $^{(12-14,17)}$, os quais observaram que o comportamento de leitura de sujeitos sem dificuldade caracterizou-se por uso equilibrado dos processos lexicais e fonológicos. Assim, os estímulos familiares (palavras de alta frequência) e os nãofamiliares (pseudopalavras) foram lidos com semelhante eficiência. Tais estudos relataram também que a leitura dos indivíduos mostrou-se sensível no nível de frequência das palavras, ou seja, os itens de alta frequência foram lidos com maior precisão do que os de baixa frequência.

Por outro lado, não se pode deixar de considerar a possibilidade de que palavras de alta e baixa frequência sejam lidas de maneira significativamente mais correta do que as pseudopalavras $^{(12-13)}$.

Os resultados desta pesquisa mostraram mais acertos na leitura das palavras de alta frequência, seguidos de acertos nas pseudopalavras e menos acertos para as palavras de baixa frequência, discordando desses autores. A liberdade de tempo concedida à leitura dos itens pode ter influenciado este resultado.

Também foi investigada a correlação entre o desempenho nas tarefas de consciência fonológica, escrita e leitura.

Em um estudo ${ }^{(3)}$ os sujeitos que apresentaram os escores mais elevados nas tarefas que avaliam as habilidades metalinguísticas mostraram também os melhores desempenhos nas tarefas de leitura e escrita.

Por outro lado, nesta pesquisa, observou-se que a correlação entre consciência fonológica e escrita foi moderada $(0,40)$, mas a correlação entre consciência fonológica e leitura $(0,11)$ e a correlação entre escrita e leitura $(0,17)$ foi bem fraca.

Uma vez que nesta pesquisa avaliamos escolares de $4^{a}$ série, estes resultados são diferentes de relatos da literatura ${ }^{(2-4,8,27)}$ que ao estudarem os processos de aquisição de leitura, afirmaram que a relação entre a consciência fonológica e leitura é provavelmente recíproca, com aumentos em uma servindo de suporte para o desenvolvimento da outra.

Por outro lado, estes achados encontram subsídio na literatura $^{(28)}$, que apesar de referir que quanto melhor a habilidade metalinguística de consciência fonológica, maior o sucesso no aprendizado da leitura e escrita, lembra também que a consciência fonológica é uma habilidade necessária, mas não suficiente para o aprendizado da leitura e escrita. É importante lembrar que a amostra foi composta de escolares de $4^{a}$ série, já distantes do processo de inicio de alfabetização.

A literatura compulsada correlacionou os níveis de consciência fonológica com habilidades de leitura e escrita, analisando a relação entre essas habilidades metalinguísticas e as diferenças nos desempenhos na leitura e escrita de palavras isoladas. Em geral os sujeitos que apresentaram os escores mais elevados nas tarefas que avaliam as habilidades metalinguísticas mostraram também os melhores desempenhos nas tarefas de leitura e escrita. Entretanto, as faixas etárias e de escolaridade mais elevadas, e os respectivos desempenhos em leitura e escrita, não foram estudados na maioria dos trabalhos, diferentemente deste.

Os resultados sugeriram que a leitura, imediatamente anterior à escrita pôde influenciar o desempenho no ditado e que a prova de escrita anterior não parece ter influenciado os resultados na leitura.

Os resultados mostraram que a leitura de itens isolados determinou mais acertos do que a escrita dos mesmos itens, independentemente do grupo estudado e das características psicolinguísticas das palavras.

Não foi possível encontrar na literatura compulsada trabalhos que, semelhantes a este, investigassem da mesma forma tais características, influências e correlações na $4^{a}$ série do Ensino Fundamental, o que prejudicou o confronto destes achados. Deve-se ressaltar também que o pequeno número de escolares em cada grupo pode ter influenciado os resultados encontrados. Entretanto, identificou-se pior desempenho, tanto na leitura, como na escrita, com palavras de baixa familiaridade, o que está de acordo com outras pesquisas realizadas.

Os resultados encontrados mostraram maior número de acertos na leitura que, associados à correlação moderada da consciência fonológica com a escrita e em comparação com a correlação bem fraca com a leitura podem sugerir que a leitura 
e escrita sejam processos diferentes, de diferentes complexidades e diferentes meios de realização.

\section{CONCLUSÕES}

Tanto na leitura quanto na escrita o desempenho dos escolares de $4^{a}$ série mostrou-se pior com palavras de baixa familiaridade, ou seja, de baixa frequência de aparecimento, do que com pseudopalavras e palavras de alta frequência. Nos desempenhos desses escolares observou-se correlação moderada da consciência fonológica com a escrita e bem fraca com a leitura.

\begin{abstract}
Purpose: To study the performance of $4^{\text {th }}$ grade students on reading, writing and phonological awareness tasks. Methods: Thirty-two $4^{\text {th }}$ grade children ( $50 \%$ of each gender), with ages between nine and 11 years, were evaluated according to the following procedure: anamnesis, reading and writing task (54 linguistic tokens), and phonological awareness task. The students were divided into two research groups and two comparison groups: GPI: carried out the writing task first, and then the reading task; GPII: completed the reading, followed by the writing task; GCI: completed only the writing items; GCII: completed only the reading items. Results: In the writing task, GPII showed the highest rates of correct answers, and GPI, GPII and GCI had better performances in writing high frequency words, followed by pseudowords and low frequency words. The reading evaluation showed that the performances of GPI, GPII and GCII were similar, and GPI and GPII had more correct answers for pseudowords, followed by high frequency words. The correlation between phonological awareness and writing was moderate, while correlations between phonological awareness and reading, and writing and reading were very weak. Conclusion: Phonological awareness was moderately correlated to the performance on the writing task, and weakly correlated to the performance on the reading task. The psycholinguistic feature low familiarity determined the highest error averages, both in reading and writing tasks.
\end{abstract}

Keywords: Reading; Handwriting; Evaluation

\title{
REFERÊNCIAS
}

1. Paula GR, Mota HB, Keske-Soares M. A terapia em consciência fonológica no processo de alfabetização. Pró-Fono. 2005;17(2):17584.

2. Salles JF, Mota HB, Cechella C, Parente MAMP. Desenvolvimento da consciência fonológica de crianças de primeira e segunda séries. PróFono. 1999;11(2):68-76.

3. Guimarães SRK. Dificuldades no desenvolvimento da lectoescrita: o papel das habilidades metalinguísticas. Psicol Teor Pesqui. 2003;19(1):33-45.

4. Queiroga BAM, Borba DM, Vogeley ACE. Habilidades metalinguísticas e a apropriação do sistema ortográfico. Rev Soc Bras Fonoaudiol. 2004;9(2):73-80.

5. França MP, Wolff CL, Moojen S, Rotta NT. Aquisição da linguagem oral: relação e risco para a linguagem escrita. Arq Neuropsiquiatr. 2004;62(2b):469-72.

6. Maluf MR, Barrera SD. Consciência fonológica e linguagem escrita em pré-escolares. Psicol Reflex Crit. 1997;10(1):125-45.

7. Barrera SD, Maluf MR. Consciência metalinguística e alfabetização: um estudo com crianças da primeira série do ensino fundamental. Psicol Reflex Crit. 2003;16(3):491-502.

8. Rego LLB, Buarque LL. Consciência sintática, consciência fonológica e aquisição de regras ortográficas. Psicol Reflex Crit. 1997;10(2):199217.

9. Meireles ES, Correa J. Regras contextuais e morfossintáticas na aquisição da ortografia da língua portuguesa por criança. Psicol Teor Pesqui. 2005;21(1):77-84.

10. Queiroga BA, Borba DM, Vogeley AC. Habilidades metalinguísticas e a apropriação do sistema ortográfico. Rev Soc Bras Fonoaudiol. 2004;9(2):73-80.

11. Pinheiro AMV. Leitura e escrita: uma abordagem cognitiva. Campinas: Editorial Psy Ii; 1994.

12. Pinheiro AMV. Caracterização e distinção entre os estágios alfabético e ortográfico na leitura e na escrita de crianças brasileiras. In: Damasceno
BP, Coudry MIH, editores. Temas em neuropsicologia e neurolinguística. São Paulo: Tec Art; 1995. p.149-56.

13. Capovilla FC, Macedo EC, Capovilla AGS, Charin S. Competência de leitura; modelos teóricos e sistemas computadorizados para avaliação de leitura silenciosa e em voz alta. In: Capovilla FC. Ciência cognitiva: teoria, pesquisa e aplicação. 1998. p. 597-676.

14. Capovilla FC, Macedo EC, Duduchi M, Capovilla A, Gonçalves MJ. Brincar de ler: o computador no diagnóstico diferencial das dislexias. Mundo Saúde. 1996;20(2):87-9.

15. Pinheiro AMV, Rothe-Neves R. Avaliação cognitiva de leitura e escrita: as tarefas de leitura em voz alta e ditado. Psicol Reflex Crit. 2001;14(2):399-408

16. Capovilla FC, Capovilla AGS, Macedo EC. Rota perilexical na leitura em voz alta: tempo de reação, duração e segmentação na pronúncia. Psicol Reflex Crit. 2001;14(2):409-27.

17. Pinheiro AMV, Rothe-Neves R. Avaliação cognitiva de leitura e escrita: as tarefas de leitura em voz alta e ditado. Psicol Reflex Crit. 2001;14(2):399-408.

18. Jourdain C, Zagar D, Lété B. Avaliar a dificuldades de leitura no adulto. In: Grégoire J. Avaliando as aprendizagens: os aportes da psicologia cognitiva. Porto Alegre: Artmed; 2000. p. 99-129.

19. Gregg N, Mather N. School is fun at recess: informal analyses of written language for students with learning disabilities. J Learn Disabil. 2002;35(1):7-22.

20. Santos MTM, Navas ALGP. Aquisição e desenvolvimento da linguagem escrita. In: Santos MTM, Navas ALGP, organizadoras. Distúrbios de leitura e escrita: teoria e prática. Barueri: Manole; 2002. p. 1-26.

21. Maluf MR, Zanella MS, Pagnez KSMM. Habilidades metalinguísticas e linguagem escrita nas pesquisas brasileiras. Bol Psicol. 2006;56(124):6792.

22. Scliar-Cabral L. Princípios aplicados à escrita. In: Scliar-Cabral L. Princípios do sistema alfabético do português do Brasil. São Paulo: Contexto; 2003. cap. 7. p. 123-49. 
23. Goulandris NK. Avaliação das habilidades de leitura e ortografia. In: Snowling MJ, Stackhouse J. Dislexia, fala e linguagem: um manual do profissional. Porto Alegre: Artmed Editora. 2004. p. 91-120.

24. Santos MTM, Pereira LD. Teste de consciência fonológica. In: Pereira LD, Schochat E. Processamento auditivo central: manual de avaliação. São Paulo: Lovise; 1997.

25. Costa MCM. Desempenho de escolares na leitura de itens segmentados e inteiros em diferentes tempos de exposição. [Monografia]. São Paulo: Universidade Federal de São Paulo. Escola Paulista de Medicina.Curso de Especialização em Fonoaudiologia; 2002.
26. Maxwell DL, Satake E. Research and statistical methods in communication disorders. EUA: William \& Wilkins; 1997.

27. Guimarães SRK. Dificuldades no desenvolvimento da lectoescrita: o papel das habilidades metalinguísticas. PsicoI Teor Pesqui. 2002;18(3):247-59.

28. Navas ALGP. O papel das capacidades metalinguísticas no aprendizado da leitura e escrita e seus distúrbios. Pró-Fono. 1997;9(1):66-9. 